\title{
Reseña del libro Estar, ser y convivir en la escuela: una mirada profunda a la violencia escolar en República Dominicana
}

\author{
Review of the book Being, being and living in school: a deep look at \\ school violence in the Dominican Republic
}

Altagracia López $z^{a}$ ORCID: 0000-0003-3672-4230

Recibido: 9/01/2020 Aprobado: 11/01/2020

Cómo citar: López, A. (2020). Reseńa del libro Estar, ser y convivir en la escuela: una mirada profunda a la violencia escolar en República Dominicana. Ciencia y Educación, 4(1), 93-95. Doi: https://doi.org/10.22206/cyed.2020.v4i1.pp93-95

Estar, ser y convivir en la escuela es un libro de la autoría de Berenice Pacheco-Salazar. Surge tras cinco años de trabajo e investigación sobre la violencia escolar en República Dominicana. Es una obra caracterizada por el rigor, la sensibilidad y el sentido ético. Un libro valioso para docentes, directivos, autoridades, investigadores, hacedores de políticas, familias; en fin, para toda persona que apuesta a la edificación de la paz.

En el contexto internacional, la violencia escolar es un tema que cada vez más forma parte de las preocupaciones cotidianas de educadores, directivos escolares, de las familias y de todos los sectores de la sociedad. En palabras de Pacheco-Salazar, la violencia escolar "imposibilita la sana convivencia, lesiona el bienestar de las personas, deshumaniza los procesos educativos y dificulta los aprendizajes" (p. 9) y es "un modo de relación cotidiana que invade todos los momentos, espacios y sujetos de la escuela, y que asume múltiples direccionalidades y múltiples manifestaciones" (p. 332). Agrega que la violencia es "la práctica de negación, cosificación y desconocimiento del otro, que escala y se incrementa ante las condiciones de naturalización e impunidad en las que se gesta y ocurre” (p. 332).

El libro, de 380 páginas, está dividido en cinco capítulos. El capítulo I presenta una exhaustiva conceptualización sobre la convivencia escolar, así como las definiciones, las consecuencias, las tipologías y los perfiles involucrados en la violencia escolar. Resulta novedoso la consideración de la no atención a la diversidad como una manifestación de la violencia de la escuela, pues revela el carácter adultocéntrico presente en las tradicionales formas de gestión y liderazgo institucional.

El capítulo II nos muestra el diseño metodológico del estudio. Haber asumido el reto de estudiar el problema de la violencia escolar desde las perspectivas y las vivencias de estudiantes y docentes nos permite aproximarnos al conocimiento de esta problemática desde miradas distintas. Se trata de un capítulo con un gran sentido formativo para todos aquellos investigadores en el campo educativo interesados en profundizar en la metodología cualitativa desde el enfoque de la voz del alumnado y en la potencialidad de las estrategias artísticas como dispositivos de recolección de información. Esto último permitió generar confianza con los estudiantes y darles la oportunidad de que se mostraran tal como son.

El capítulo III presenta los hallazgos obtenidos tras haber realizado una inmersión de ocho meses en dos centros educativos públicos, trabajando con docentes y con estudiantes en edades comprendidas entre 9 y 16 años.

a Instituto Tecnológico de Santo Domingo (INTEC), República Dominicana

Correo-e: altagracia.lopez@intec.edu.do 
En República Dominicana la violencia escolar es un flagelo presente en el día a día de los centros educativos, en una dinámica de violencia que no solo ocurre entre estudiantes, sino también de docentes hacia estudiantes, situación ante la cual no deberíamos perder nuestra capacidad de asombro, sino reforzar nuestra disposición de ser parte de los que aportan a la solución.

El libro de Berenice Pacheco-Salazar nos devela a un y una docente que asume la violencia verbal y física como parte de su cotidianidad y como mecanismo disciplinario; que tiene "interiorizado un modelo de relacionamiento violento” ( $p$. 177) con el estudiante y que no cuenta "con referentes relacionales armónicos y horizontales” (p. 177). Esta situación puede reflejar que el profesorado está reproduciendo en su quehacer docente lo aprendido de quienes fueron sus formadores; o puede también revelar, como afirma la autora, "los contextos de violencia de donde proceden los propios docentes" (p. 177). Por lo que es vital que quienes forman a los futuros y actuales maestros y maestras modelen estrategias de aprendizaje innovadoras, participativas e inclusivas que ayuden a los futuros docentes a desaprender relaciones de violencia y aprender estrategias de prevención y convivencia.

Estar, ser y convivir en la escuela nos retrata a unas escuelas que el estudiantado denomina como "cárceles". Los hallazgos son desgarradores: violencia interiorizada como una forma de diversión, naturalizada como parte de la identidad masculina y justificada en el ejercicio hacia las alumnas; el cuerpo femenino construido como objeto sexual, las redes sociales como escenario para las ciberviolencias, el no quedarse dao como la principal estrategia de afrontamiento por parte del estudiantado, la no atención a la diversidad como violencia institucional, entre otros.

A pesar de tan desalentador escenario, la autora logra perfilar alternativas, rutas de cambio e incluso visualizar esperanza. Los capítulos IV y $\mathrm{V}$ presentan las conclusiones, discusiones y recomendaciones que, sin lugar a duda, tienen la potencialidad de impactar positivamente en las políticas educativas de República Dominicana y la región.

Berenice Pacheco-Salazar nos invita a comprender la violencia escolar desde su complejidad y a prevenirla desde un abordaje intersectorial e integral. La autora sugiere aproximarse a la violencia escolar "desde una mirada integral que identifique las condiciones estructurales y culturales que la generan, reproducen y perpetúan” (p. 335). Propone, con lucidez y certeza, un conjunto de seis acciones para la construcción de la convivencia escolar que van desde la formulación de políticas públicas hasta la transformación del ámbito pedagógico-curricular de las aulas.

Quiero destacar, de manera particular, que resulta necesario que las instituciones que ofertan formación inicial y continua del profesorado asuman el reto de que los profesionales de la educación posean las competencias necesarias para una efectiva gestión de aula, con reales espacios de convivencia, desde una cultura de paz y de vivencia de valores. Es necesario eliminar de la escuela la concepción de violencia como un mecanismo disciplinario, así como la creencia de que la escuela no tiene responsabilidad alguna ante esta problemática. El horizonte debería estar colocado en transformar la escuela hacia una dialogante, inclusiva y participativa.

Para la autora, asumir este desafío requiere de la acción comprometida de toda la comunidad educativa, mediante la puesta en marcha de "procesos formativos centrados en estrategias metodológicas activas y vivenciales que consideren la reflexión sobre las propias historias de vidas personales y profesionales y sobre los momentos y formas en que han sido víctimas de violencia o, incluso, victimarios" (p. 337). Asimismo, propone que la formación docente y de equipos de gestión se centre en el logro de cuatro objetivos:

1. Sensibilizar y formar en el conocimiento de las raíces estructurales y culturales de la violencia, sus características y sus manifestaciones.

2. Contribuir al desarrollo de competencias socioemocionales y ciudadanas a fin de ser agentes de cambio en el entorno escolar mediante:

- la deconstrucción de los cimientos adultocéntricos en la pedagogía tradicional,

- el florecimiento del sano afecto, la estima y la empatía,

- el desarrollo de competencias ciudadanas y socioemocionales en el estudiantado. 
3. Fortalecer las competencias profesionales para desarrollar procesos áulicos basados en el aprendizaje y el trabajo cooperativo, la atención a la diversidad, la motivación y la emoción.

4. Capacitar en el manejo de estrategias de intervención psicoeducativas que les permitan identificar, atender y prevenir las distintas manifestaciones y tipologías de violencia escolar a partir de estrategias integrales, innovadoras, eficaces y coherentes con la realidad de su contexto y que permitan trascender:

- de lo punitivo a lo preventivo,

- de la vigilancia a la confianza,

- de la imposición al diálogo,

- de la exclusión a la participación,

- de la segregación a la coeducación,

- de la indiferencia a la empatía (p. 337).

Sin lugar a duda, quien lea Estar, ser y convivir en la escuela, de Berenice Pacheco-Salazar, quedará interpelado a ver, a comprender, a accionar. Tal y como expresó Ángela Hernández (2019), Premio Nacional de Literatura, este es un libro para transformar nuestra visión (...) Quien lee 'Estar, ser y convivir en la escuela' no podrá permanecer indiferente.

\section{Referencias}

Pacheco-Salazar, B. (2019). Estar, ser y convivir en la escuela: una mirada profunda a la violencia escolar en República Dominicana. Santo Domingo: Organización de Estados Iberoamericanos para la Educación, la Ciencia y la Cultura (OEI), Instituto Tecnológico de Santo Domingo (INTEC) e Instituto Nacional de Formación y Capacitación del Magisterio (Inafocam).

Hernández, A. (2019, 21 de diciembre). Estar, ser y convivir en la escuela: un libro para transformar nuestra visión. Plenamar. https://plenamar.do/ 2019/12/estar-ser-y-convivir-en-la-escuelaun-libro-para-transformar-nuestra-vision/ 